\title{
Implementasi Metode Rapid Application Development (RAD) Dan Metode Alphabetical Filling Pada E-Arsip Di Fakultas Matematika Dan IPA Berbasis Web
}

\author{
Andoko Putra*1, ${ }^{*}$ cuk Darusalam ${ }^{2}$, Ratih Titi Komalasari ${ }^{3}$ \\ ${ }^{1,2}$ Universitas Nasional; Jl.Sawo Manila, Pejaten Ps. Minggu Jakarta 12520 \\ ${ }^{3}$ Jurusan Sistem Informasi, FTKI UNAS, Jakarta \\ e-mail: \\ *11andokoputra90@gmail.com, ${ }^{2}$ ucuk.darussalam@gmail.com, ${ }^{3}$ ratih.titi@ civitas.unas.ac.id
}

\begin{abstract}
Abstrak
Perkembangan teknologi yang cepat memberi dampak positif atas inovasi-inovasi yang berbasis teknologi. Khususnya pada tata kelola administrasi telah berubah dari konvensional menjadi sistem. Peran teknologi sangatlah penting pada perubahan ini. Terlihat pada Fakultas Matimatika dan IPA Universitas Semarang mengubah tata kelola pelayanan arsip berbasis web. Sistem ini menggunakan metode Alphabetical Filling dan metode Chronology System. Dimana metode ini berguna untuk memudahkan penemuan data arsip berdasarkan abjad dan tanggal upload berkas. Sedangkan pada pengembangan E- Arsip menggunakan metode pemgembangan Rapid Application Development (RAD) dimana terdapat 3 proses atau langkah kerja yang membuat sistem dapat terselesaikan dalam waktu yang singkat. Pengujian yang dilakukan dengan black box memperlihatkan proses procedural pada sistem dapat berjalan dengan baik dan sesuai yang diharapkan.
\end{abstract}

Kata kunci-Archives, Rapid Application Development, Alphabetical Filling, Chonology System, Uml Diagram

Abstract
Rapid technological developments have a positive impact on technology-based innovations. Especially in the administration of governance has changed from conventional to a system. The role of technology is very important in this change. Seen in the Faculty of Mathematics and Natural Sciences, University of Semarang changing the governance of webbased archive services. This system uses the Alphabetical Filling method and the Chonology System method. Where this method is useful to facilitate the discovery of archive data alphabetically and file upload date. Meanwhile, the development of E-Archives uses the Rapid Application Development (RAD) method where there are 3 processes or work steps that make the system complete in a short time. Tests carried out with black blocks show that the procedural process on the system can run well and as expected.

Keywords-Archives, Rapid Application Development, Alphabetical Filling, Chronology System, Uml Diagram

\section{PENDAHULUAN}

Perkembangan teknologi dan perubahan tata kelola kehidupan sangat berkembang cepat. Ini jutru setiap manusia untuk selalu mengikuti perubahan dan selalu meng-upgrade kemampuan baik dibidang teknologi dan bidang lainnya. Perubahan ini juga berimbas pada sektor pendidikan, dimasa sekarang kita tidak akan lepas dengan fasilitas dari hasil inovasi 
teknologi. Teknologi website dapat kita ambil contoh, website yang menghubungkan server dengan user dapat melakukan interaksi yang interns kapanpun dan dimanapun. Ini menjadi salah satu teknologi yang dapat memudahkan pekerjaan manusia. Server yang dapat menyimpan data dalam bentuk berbagai jenis dalam jumlah yang besar. Data yang disimpan didalam server dapat di request kapanpun disaat kita butuhkan [1].

Maka oleh sebab itu, berdasarkan hal ini penulis merancang sistem terpadu atau terintegrasi untuk menyimpan data di server. Data ini akan tersimpan dengan baik untuk waktu yang lama. Penulis merasa cocok untuk sistem ini diterapkan pada pelayanan E-Arsip pada Fakultas Matematika dan IPA. Sistem arsip yang selama ini dikenal hanya sebatas mempermudah masuk dan keluarnya surat serta berita acara, tentunya tidak dapat mempermudah dalam memberikan sebuah keputusan kepada suatu program yang tepat sasaran.[2]

Dasar permasalahan yang menjadi alasan dibuat sistem E-Arsip pada Fakultas Matematika dan IPA di Universitas Semarang adalah dimana proses pelayanan arsip masih dalam bentuk kertas dan masih menggunakan sistem yang konvensional. Pada masalah ini mengambarkan proses surat menyurat yang dilakukan oleh sekretaris kepada kepala program studi di Fakultas Matematika dan IPA di Universitas Semarang yang awalnya masih konvensional. Pengelolaan surat masuk dan keluar berbasis website dapat menyimpan data dalam satu tempat sehingga memudahkan dalam pencarian data.

Maka oleh sebab itu penulis bertujuan untuk mempermudah tata kelola pelayanan surat, dan data arsip menjadi lebih terintegrasi, cepat dan efesien. Penulis berharap sistem ini dapat mempercepat proses pelayanan surat masuk dan keluar serta data arsip yang dapat terjaga dengan baik.

Sistem pakar dapat memecahkan masalah dan mengatur pengelolaan data surat masuk dan keluar dalam satu sistem yang dapat dipantau dan di kelola pada satu tempat yang terintegrasi pada sistem. Diadakannya penelitian ini bertujuan untuk mempermudah tata kelola pelayanan surat, dan data arsip menjadi lebih terintegrasi, cepat dan efesien. Penulis berharap sistem ini dapat mempercepat proses pelayanan surat masuk dan keluar serta data arsip yang dapat terjaga dengan baik.

Pada penelitian sebelumnya penerapan metode RAD pada pengembangan sistem informasi data toko dapat memudahkan user dalam mengelola data toko dan bentuk keamanan data yang terjamin [2]. Database MYSQL dan bahasa pemprograman PHP adalah pilihan terbaik untuk mengembangkan sistem berbasis website. Ini terbukti pada penelitian sebelumnya kebanyakan sistem di kembangkan dengan teknologi tersebut [3][4].

\section{METODE PENELITIAN}

\subsection{Kerangka Kerja Penelitian}

Pada penelitian ini metode yang digunakan dalam implementasi sistem E-arsip adalah metode (RAD) Rapid Application Development. RAD ialah seperangkat teknik terintegrasi, panduan serta tools yg memfasilitasi kebutuhan sistem software pelanggan dalam waktu singkat.

RAD mengacu pada prosedur pengiriman produk sesuai dengan jadwal produksi pada gambar produk. Keberhasilan menggunakan RAD berasal dari seberapa baik tim dapat memahami kebutuhan dan tujuan konsumen yang terkait dengan proyek tertentu.

RAD adalah seperangkat teknik yang dirancang untuk memanfaatkan prototyping dan aplikasi bersama untuk tujuan pengembangan aplikasi yang cepat dan efisien. Dari definisi dan definisi RAD dalam konteks ini, terlihat bahwa RAD dapat diterapkan pada pengembangan aplikasi.8].

Putra, et., al [Implementasi Metode Rapid Application Development (RAD) dan Metode Alphabetical Filling pada E-Arsip di Fakultas Matematika dan IPA Berbasis Web 
Tahap-tahap penelitian yang dilakukan sebagai berikut:

a. Tahap Requirements Planning

Tahapan ini merupakan tahap yang menjelaskan gambaran umum atau analisis dari sistem baik berupa menentukan teknologi yang dipakai, menggambarkan sistem dalam analisa pengguna atau user dan kompenen - komponen dari sistem.

b. Tahap Design Workshop

Tahapan ini merupakan tahap dalam proses perancangan baik rancangan database, rancangan struktur menu dan rancangan interface atau antarmuka.

c. Tahap Implementation

Tahapan ini merupakan tahap yang menerapkan implementasi pada sistem baik dari proses pemprograman dan evaluasi dari hasil ujicoba sistem baik dalam aspek funtionality, reability, usability dan efficiency.

\subsection{Objek Penelitian}

Adapun objek penelitian yang peneliti lakukan adalah Arsip surat masuk dan surat keluar pada Fakultas Matematika dan IPA di Universitas Semarang.

\subsection{Operasional Variabel}

Operasional variabel dalam penelitian ini adalah bagaimana mengelola dokumen atau surat dengan mengimplementasikan aplikasi berbasis web, berupa variabel yang digunakan adalah [8]

1. Surat Masuk

2. Surat Keluar

\subsection{Metode Alphabetical Filling}

Metode Alphabetical Filing System adalah sistem penyimpanan dan pencarian kembali arsip berdasarkan abjad (Ria Resti, 2020). Sistem ini sudah lazim digunakan pada sistem konvensional dan dapat digunakan dan diterapkan pada sistem berbasis database. Penggunaan Index pada pencarian data yang tersusun berdasarkan abjad dari nama orang, tujuan, dan tanggal upload.[11] 
1. MEMBUAT PEMBATASN ORDER BY A-Z (NAMA SURAT)
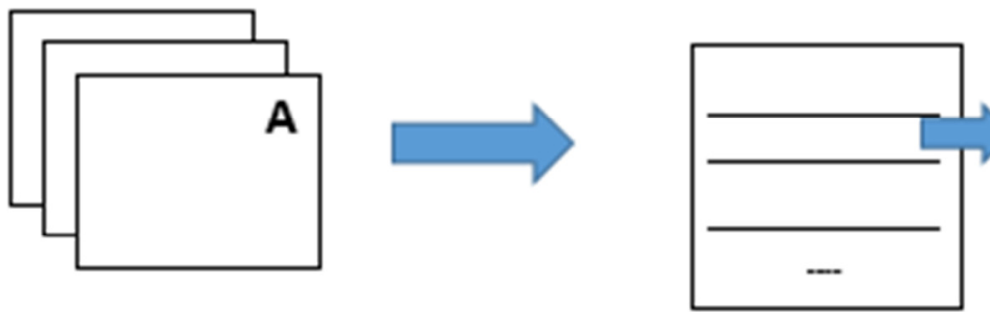

2. MENGINDEKS NAMA SURAT DAN TANGGAL SURAT

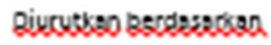
obiad cosem surat.

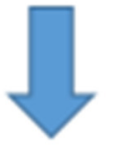

3 MEMBUAT DAFTAR Pustaka. 4. DIURUTKAN BERDASRJAB ABJAD PADA GUIDE INDEKS

NAMA SURQTi SURAT PERIZINAN HIMPUNAN MAHASWA

KABEXAA NLWS SURAT DIAWAU HURUF S MAKA INDEKS AKAN DI LETAKAN DIURUTAN ABJAD "S"

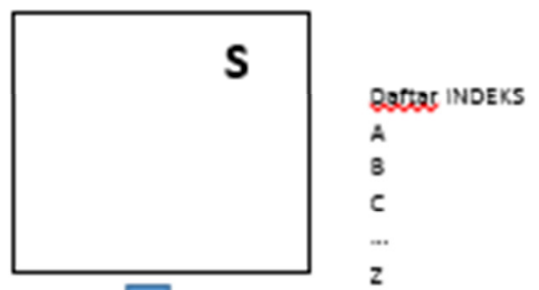

3.QSWUPAX DATABASE ORDER BY NAMA SURAT TERSUSUN DENGAN RAPI

I

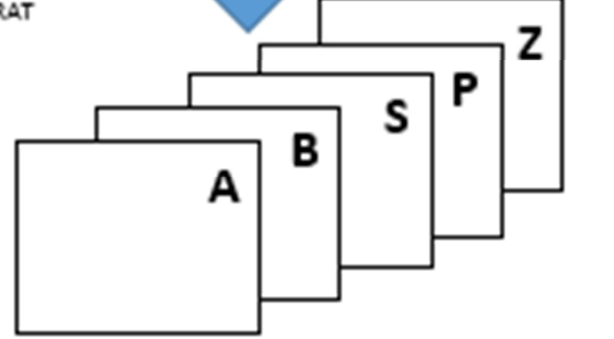

Gambar 3. Langkah- Langkah Alphabetical Filling

Pada penerapan metode pada sistem, data yang diinput oleh sekretaris akan berisi field berupa nama surat, tanggal surat, dan tujuan surat. Dari penamaan nama surat akan di deteksi urutan berdasarkan nama surat pada sistem tersebut. Diurutkan berdasarkan abjad dari nama surat. Pada arsip akan terlihat urutan urutan data berdasarkan nama surat dari masing-masing abjad yang diurutkan.

\subsection{Metode Chronology System}

Metode Chronology System adalah sistem penyimpanan data yang disusun berdasarkan waktu, tahun dan tanggal penyimpanan data. Penerapan Chronology System pada sistem ini terlihat pada surat masuk atau surat keluar adalah dengan dilabelkan berdasarkan pada waktu upload atau penyimpanan data tersebut.[12] 

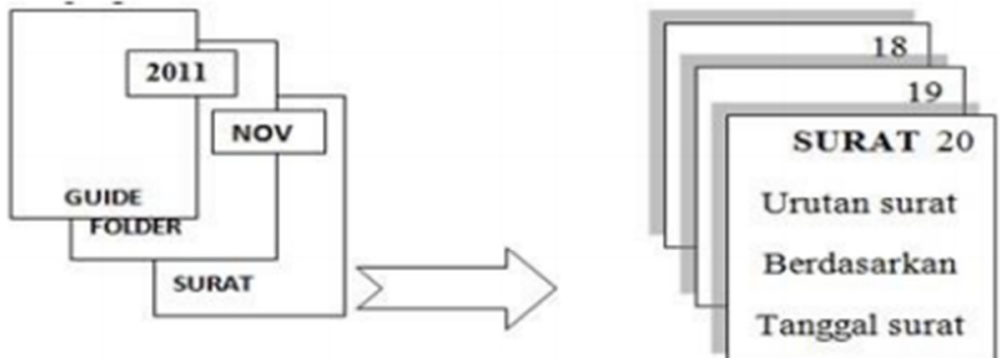

Gambar 4. Langkah Chronology System

Pada gambar 4 merupakan langkah yang dilakukan pada metode chronology System dimana setiap data yang akan masuk ke sistem akan menyimpan index berupa tanggal upload dan kode unik dari data tersebut. Tanggal ini akan diurutkan berdasarkan hari, bulan, dan tahun. Proses ini sangat memudahkan filtering data yang begitu banyak agar dapat ditemukan dengan cepat dan tepat.[12]

\section{HASIL DAN PEMBAHASAN}

Pada sistem ini menggunakan proses pengembangan RAD dimana proses dimulai dari tahap requiments planning, tahap desain workshop dan tahap terakhir implementasi. Langkah langkah pengembangan RAD dapat dijelaskan dibawah ini.

\subsection{Tahap Requirements Planning}

\subsubsection{Analisa Kebutuhan}

Pada analisa kebutuhan yaitu mengidentifikasi kebutuhan sistem yang dibutuhkan dalam mencapai tujuan yang akan di kerjakan.

a. Kebutuhan perangkat keras yang digunakan yaitu 1 buah laptop dengan spesifikasi: processor Intel@ Core ${ }^{\mathrm{TM}}$ i5 CPU M @2.27 Ghz, Ram 6 GB, Sistem Operasi Windows 10 64bit.

b. Kebutuhan perangkat lunak yang digunakan: XAMPP 3.2.4 sebagai server side, MYSQL 4.8.2 sebagai perancangan basis data, Visual Studio Code sebagai text editor, Browser Chrome.

\subsection{Tahap Desaign Workshop}

\subsubsection{Perancangan Basis Data}

Pada implementasi basis data pada sistem E- Arsip ini menggunakan DBMS MYSQL dengan nama database db_arsip dan memiliki 8 table dengan memiliki relasi satu sama lain [10].

Putra, et., al [Implementasi Metode Rapid Application Development (RAD) dan Metode Alphabetical Filling pada E-Arsip di Fakultas Matematika dan IPA Berbasis Web 


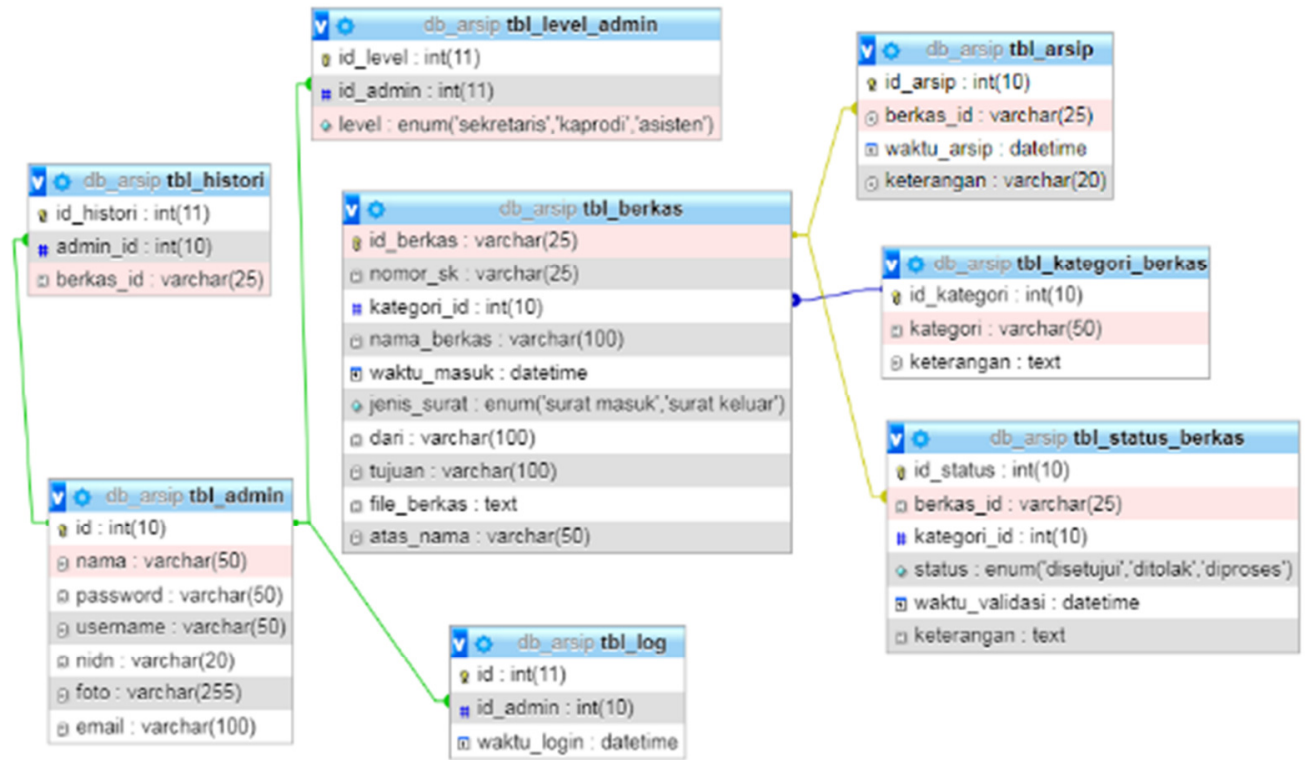

Gambar 5. Skema Database

\subsubsection{Perancangan Sistem}

a. Use Case Diagram

Merupakan perancangan model yang menjelaskan perilaku antara user yang berkaitan dengan sistem yg dikembangkan. Dalam gambar 6 terdapat dua user yaitu Sekretaris dan Kaprodi [6].

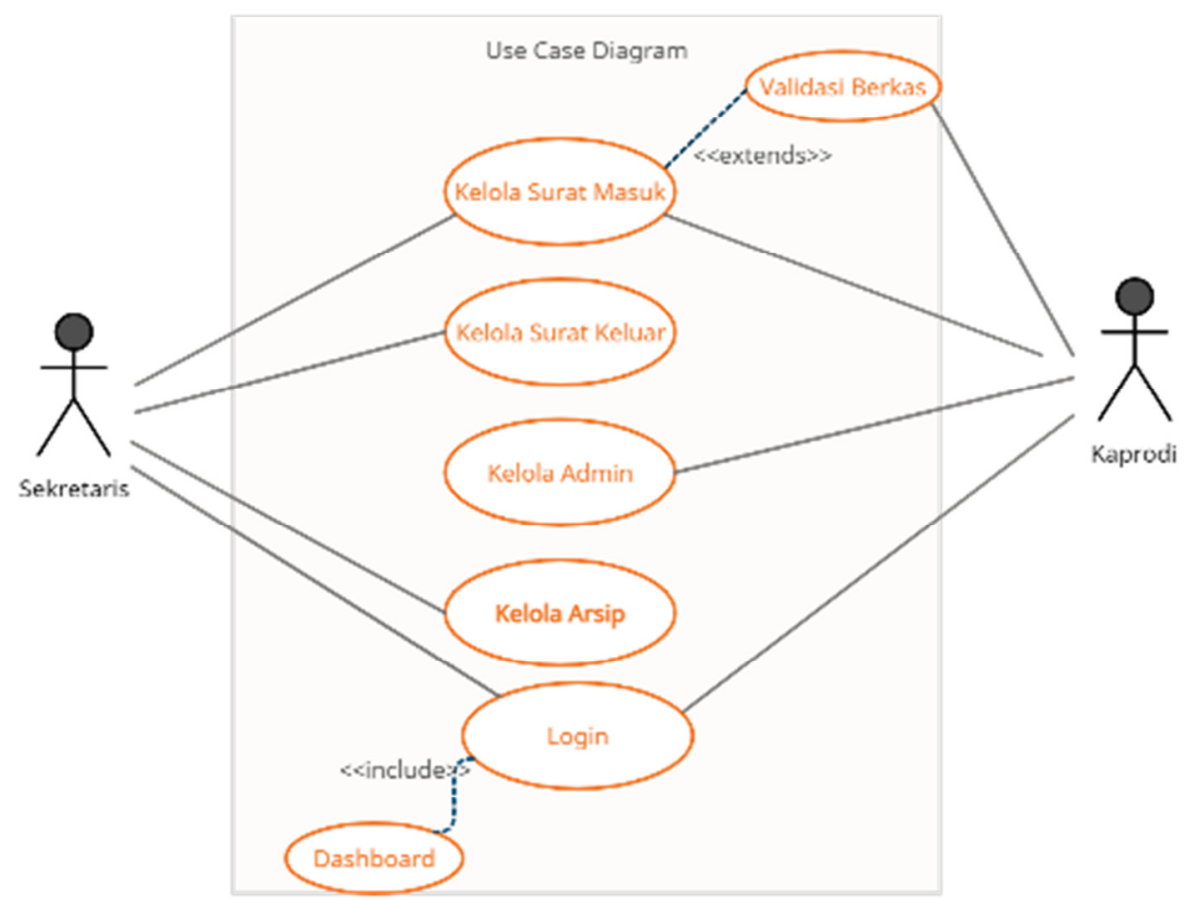

Gambar 6. Use Case Diagram

Putra, et., al [Implementasi Metode Rapid Application Development (RAD) dan Metode Alphabetical Filling pada E-Arsip di Fakultas Matematika dan IPA Berbasis Web 
Pada use case diagram terdapat 2 peran yaitu sekretaris dan kaprodi. Kedua peran ini memiliki tugas dan hak akses masing- masing. Sekretaris sebagai menginputkan surat masuk, menyimpan surat keluar kedalam database arsip, sedangkan kaprodi sebagai validasi data surat masuk yang telah dinputkan oleh sekretaris agar diteruskan ke data arsip

b. Activity Diagram

Activity diagram singkatnya adalah Diagram aktiftas lebih memfokuskan diri pada eksekusi dan alur system dari pada bagaimana system itu dibangun [6].

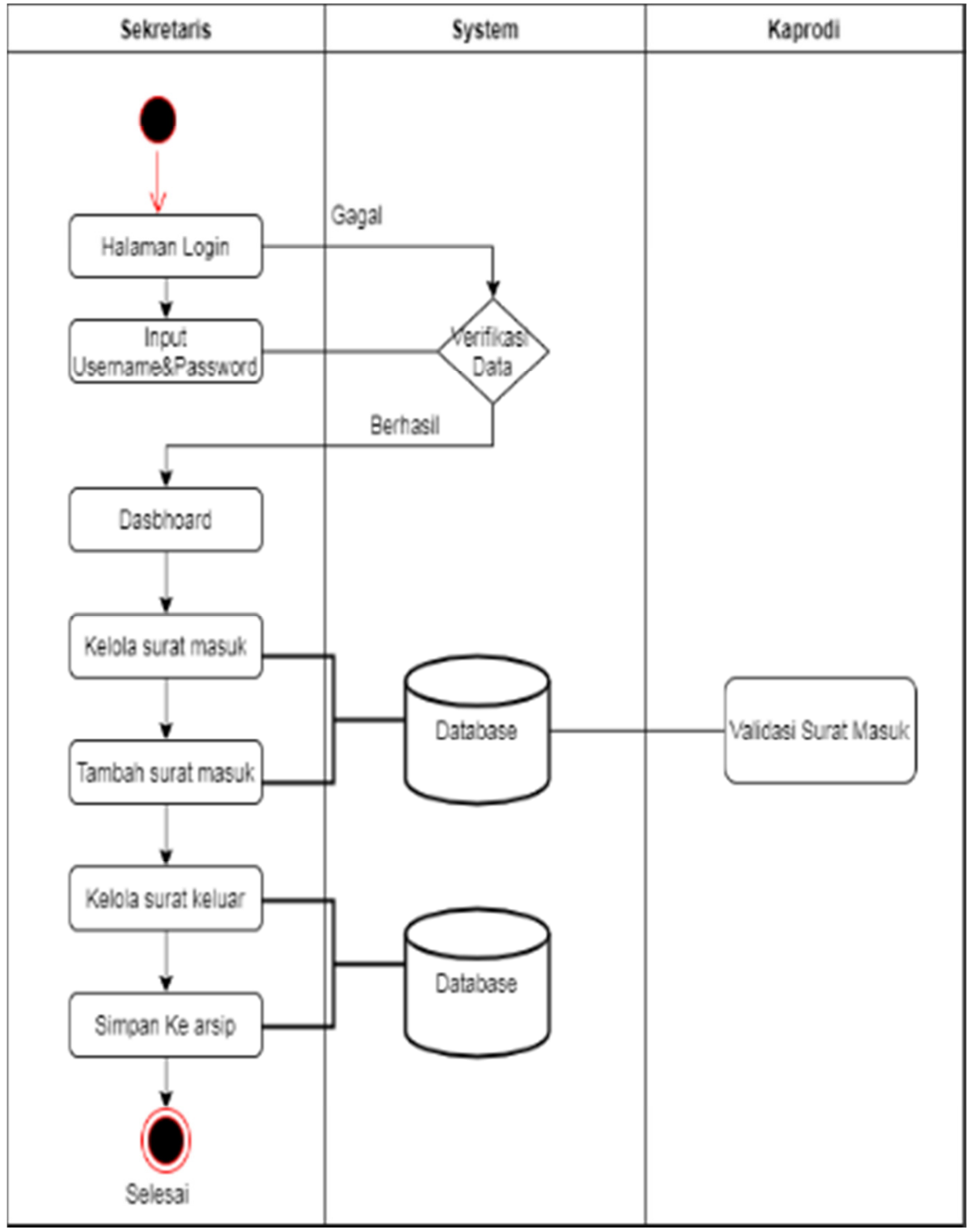

Gambar 7. Activity Diagram

Pada gambar 7 terdapat activity diagram yang menjelaskan proses alur kerja dimulai dari login, menginputan data surat masuk, validasi data oleh kaprodi, hingga surat keluar yang di simpan kedalam data arsip. 


\subsection{Tahap Implementasi}

\subsubsection{Implementasi Sistem}

Pada Implementasi sistem E-Arsip ini pemprograman menggunakan bahasa PHP versi 7.3 dan database menggunakan DMBS MYSQL sedangkan interface sistem menggunakan framework CSS Boostrap versi 4. Berikut tampilan dari sitem E-Arsip diantaranya [8]:

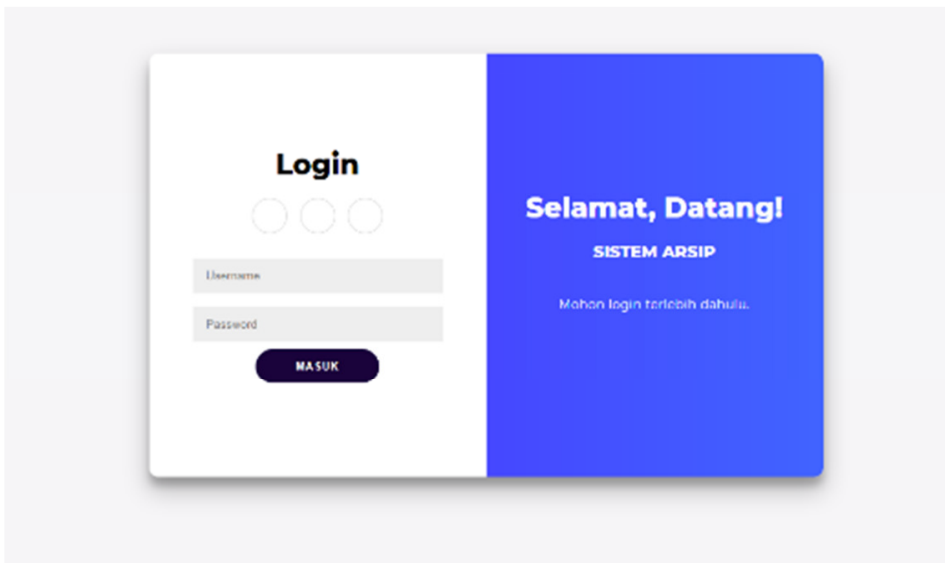

Gambar 6. Interface Login Admin

Pada gambar 6 merupakan tampilan login untuk sekretaris dan kaprodi dengan akses menggunakan username dan password. Data yang dimasukan akan di cek dengan database apakah sesuai atau tidak. Untuk password disini menggunakan hasing MD5 untuk enskripsi data.

\section{造-}

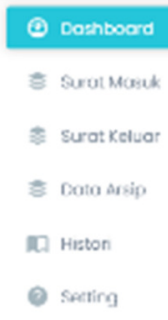

하
Dashboard Herre > Doanhweret
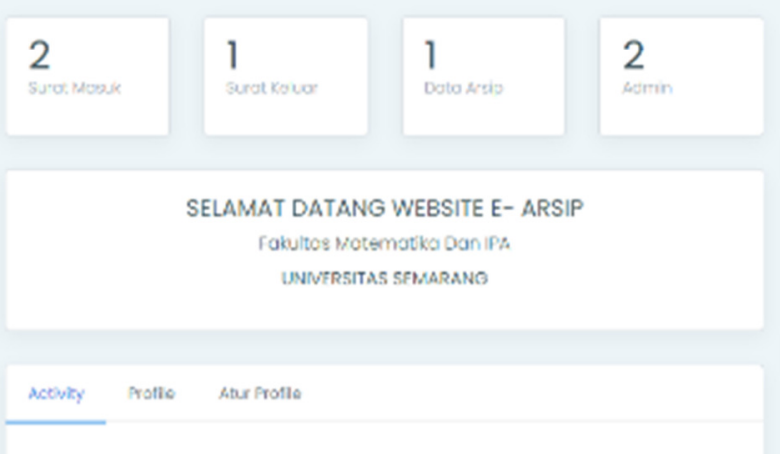

\&.

Gambar 7. Interface Dashboard Sekretaris

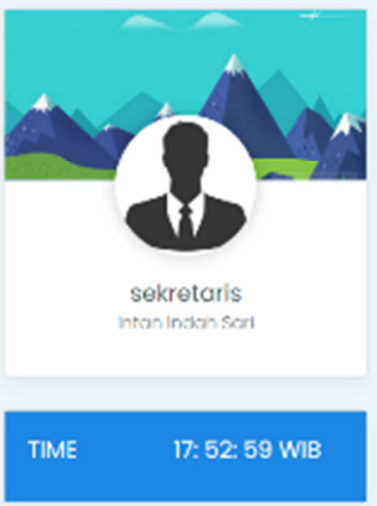

Pada gambar 7 merupakan tampilan dashboard sekretaris dimana ini tampilan pertama yang akan dilalui setelah proses login berhasil. Disebelah kiri terdapat pilihan menu diantaranya dashboard, surat masuk,surat keluar, data arsip, histori dan setting.

Putra, et., al [Implementasi Metode Rapid Application Development (RAD) dan Metode Alphabetical Filling pada E-Arsip di Fakultas Matematika dan IPA Berbasis Web 


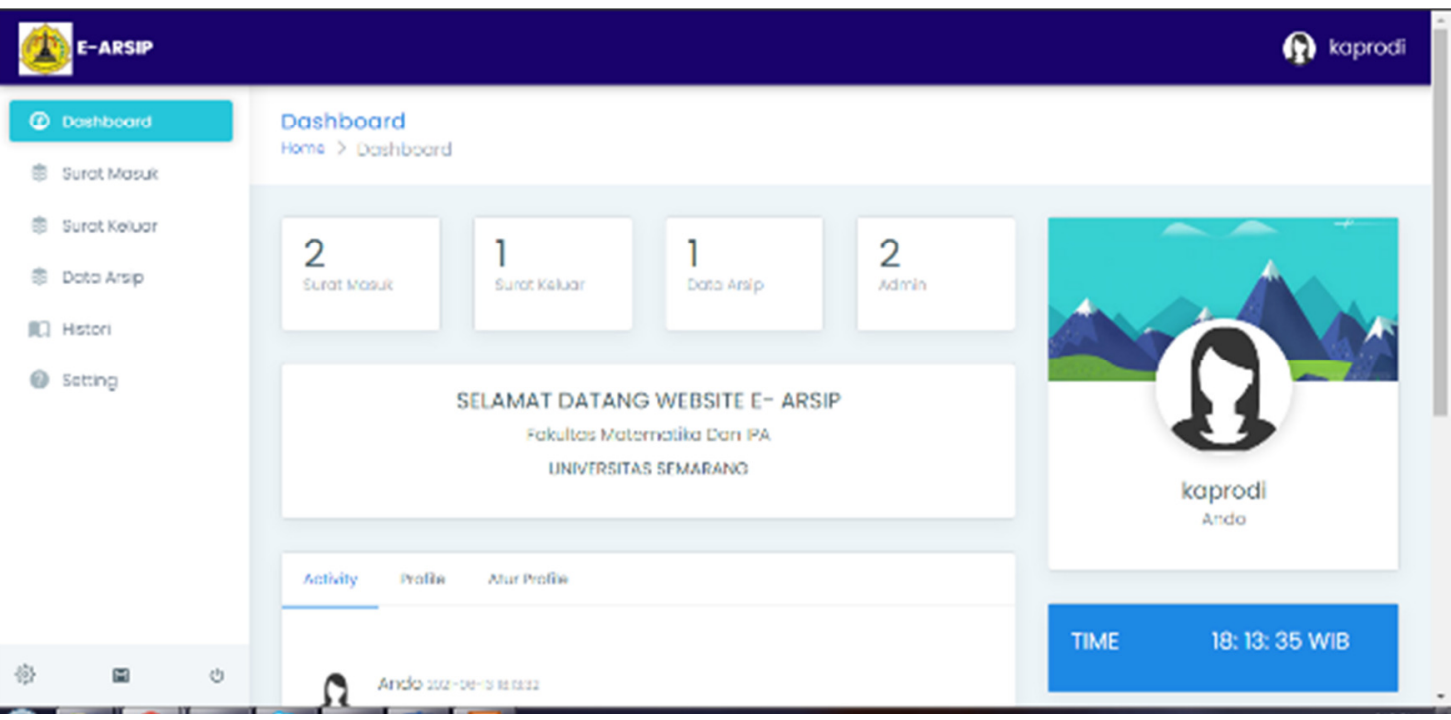

Gambar 8. Interface Dashboard Kaprodi

Pada gambar 8 merupakan tampilan dashboard kaprodi dimana ini tampilan pertama yang akan dilalui setelah proses login berhasil. Tampilan depan terlihat halaman data surat masuk, surat keluar, data arsip dan data admin.

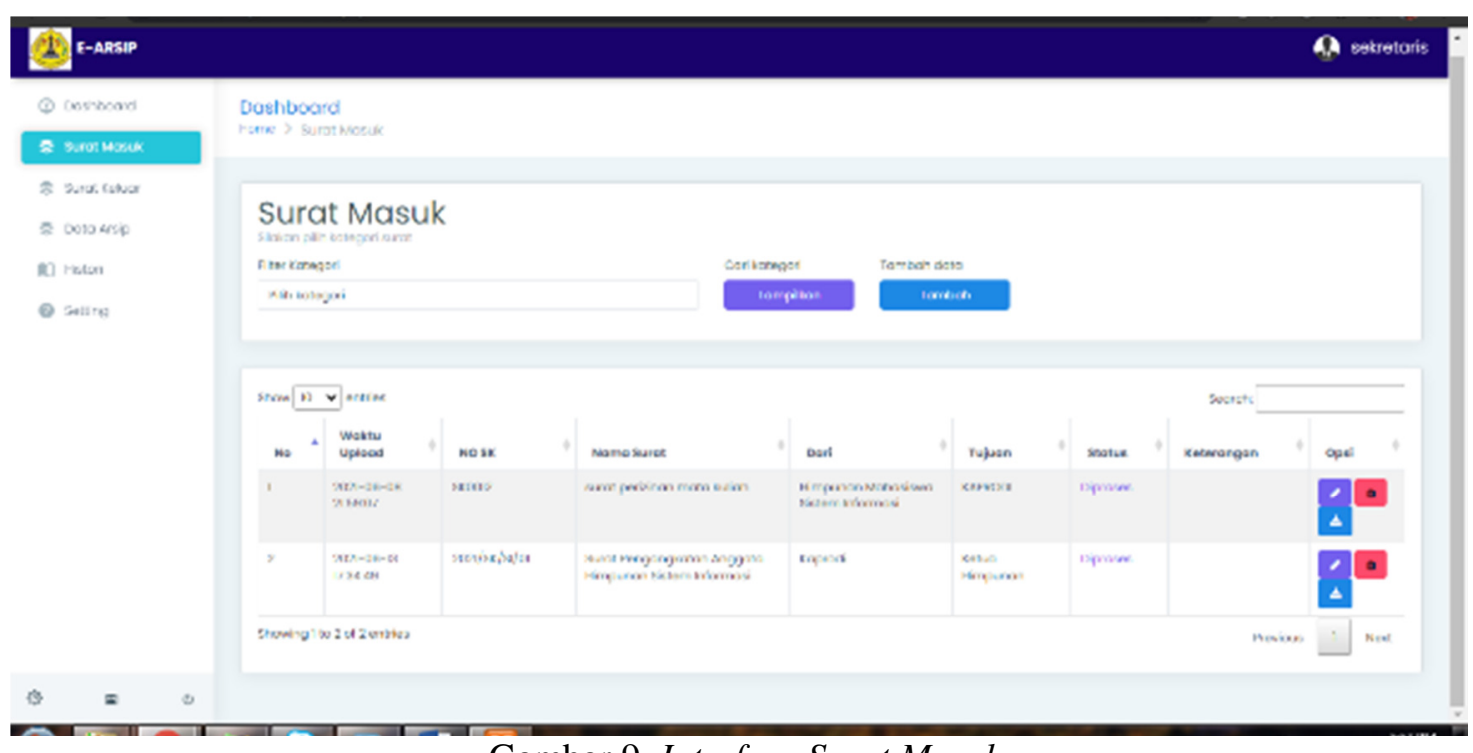

Gambar 9. Interface Surat Masuk

Pada gambar 9 merupakan tampilan data surat masuk. Sekretaris dapat mengelola surat masuk baik dengan menambah data baru, mengubah dan menghapus data surat. 


\section{E-ARSP}

\begin{tabular}{|c|}
\hline Osorrocoro \\
\hline 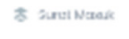 \\
\hline * surkever \\
\hline$\approx$ octos sispo \\
\hline$x+20$ \\
\hline $0=5$ inting \\
\hline
\end{tabular}

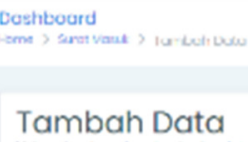

Gambar 10. Interface Tambah Data Surat

Pada gambar 10 merupakan tampilan menambah data surat yang terdiri data inputan seperti nomor sk, nama berkas, kategori, jenis surat dari / tujuan surat, atas nama, dan file berkas. Tambah surat ini hanya bisa diakses oleh sektetaris saja.

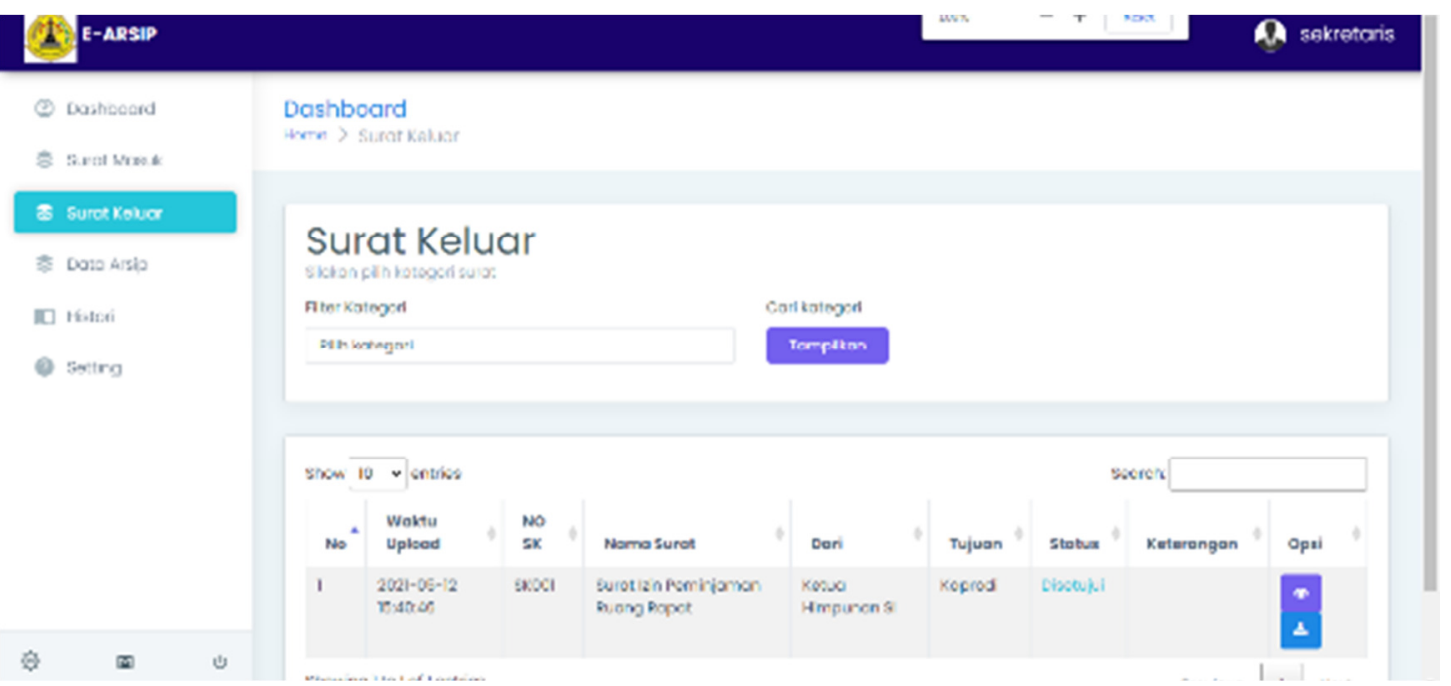

Gambar 11. Interface Surat Keluar

Pada gambar 11 merupakan tampilan data surat keluar dimana surat yang telah disetujui atau ditolak oleh kaprodi akan di simpan pada data surat keluar. Surat keluar yang di telah diproses oleh kaprodi tadi akan ditumpuk pada sebuah table yang terdiri berdasarkan urutan abjad dari nama orang, tujuan, dan tanggal upload. Proses penemuan ini didasarkan dan disesuai dengan abjad dari nama orang, tujuan, dan tanggal upload. [11] 


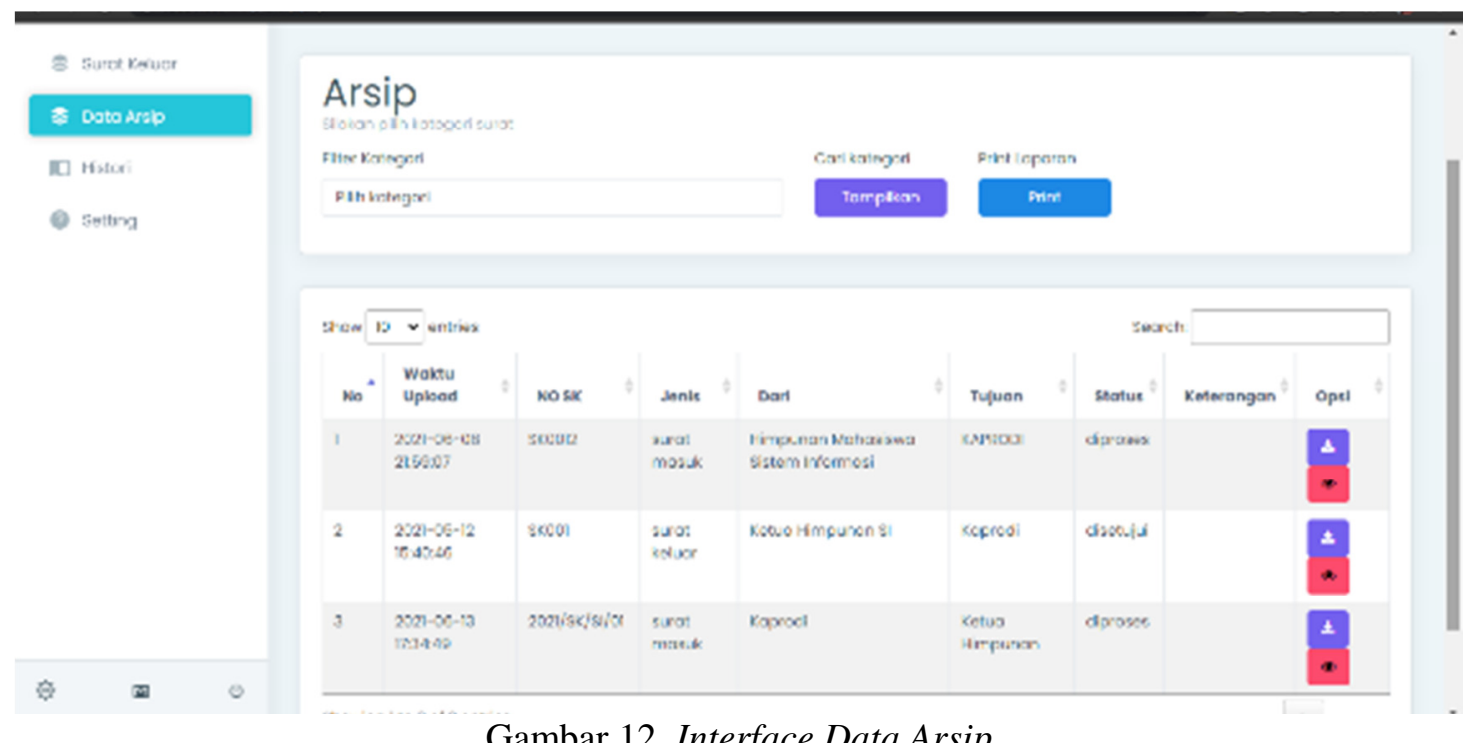

Gambar 12. Interface Data Arsip

Pada gambar 12 merupakan tampilan data arsip dimana data ini akan menyimpan data surat keluar yang telah di validasi oleh kaprodi. Pada data diatas terlihat bahwa menggunakan metode Alphabetical Filling dimana data dikelompokan berdasarkan abjad dari nama surat yang didefinisikan dari awal di inputkan. Ini dapat mempermudah dalam penyusunan data dari berdasarkan abjad A - Z. Data ini dapat di export dalam file excel sebagai laporan yang akan diperlukan sebagai arsip fakultas. Pada data arsip perlu di filtering berdasarkan waktu upload yang terdiri atas tahun, bulan dan tanggal dari penyimpan data arsip. Maka oleh sebab itu penulis menggunakan metode Chronology System untuk mengatasi proses pencarian pada data arsip ini. Proses ini dapat memudahkan sekretaris dalam mencari data surat berdasarkan tahun, bulan dan tanggal validasi atau upload berkas. [12]

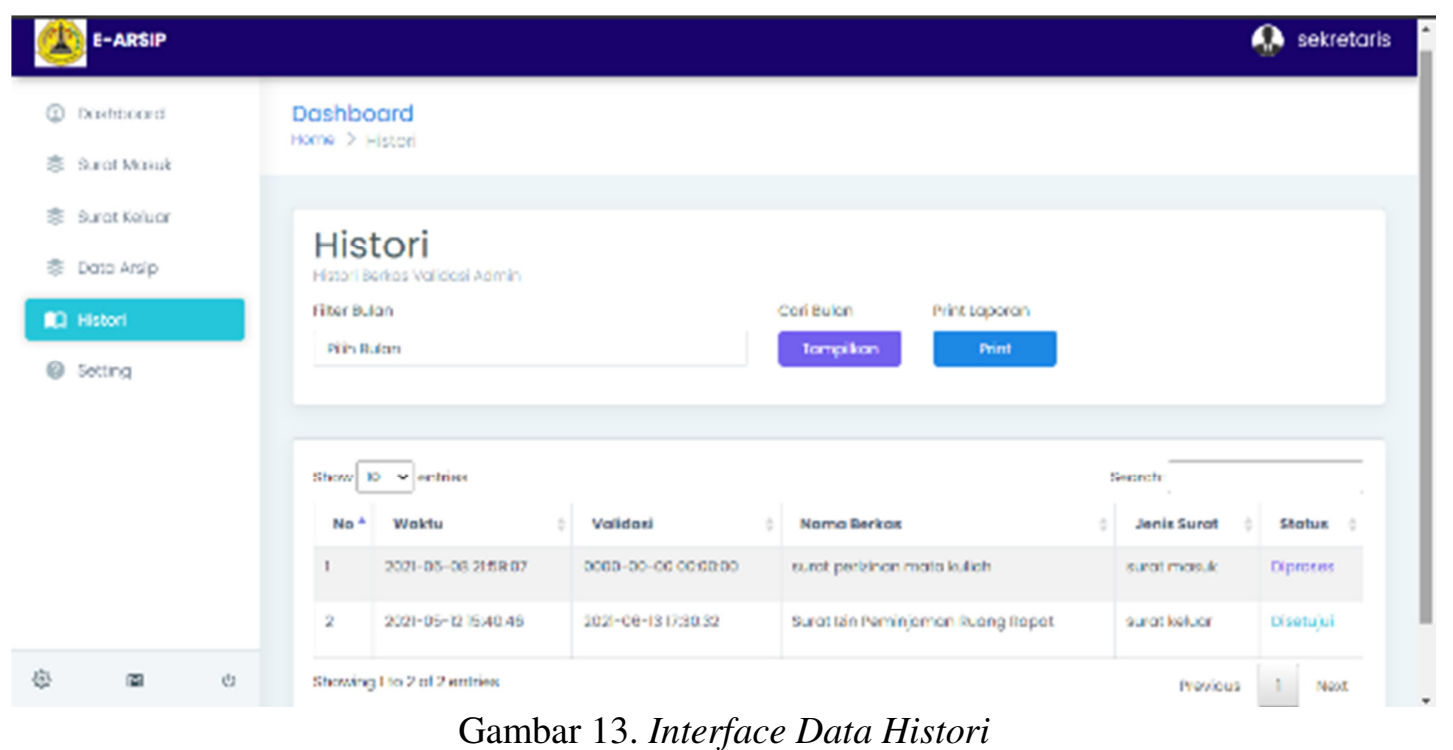

Gambar 13. Interface Data Histori 
Pada gambar 13 merupakan tampilan histori dari proses data surat. Data histori yang ditampilkan berdasarkan waktu upload, keterangan surat dan status surat yang telah di proses oleh sekretaris dan kaprodi.

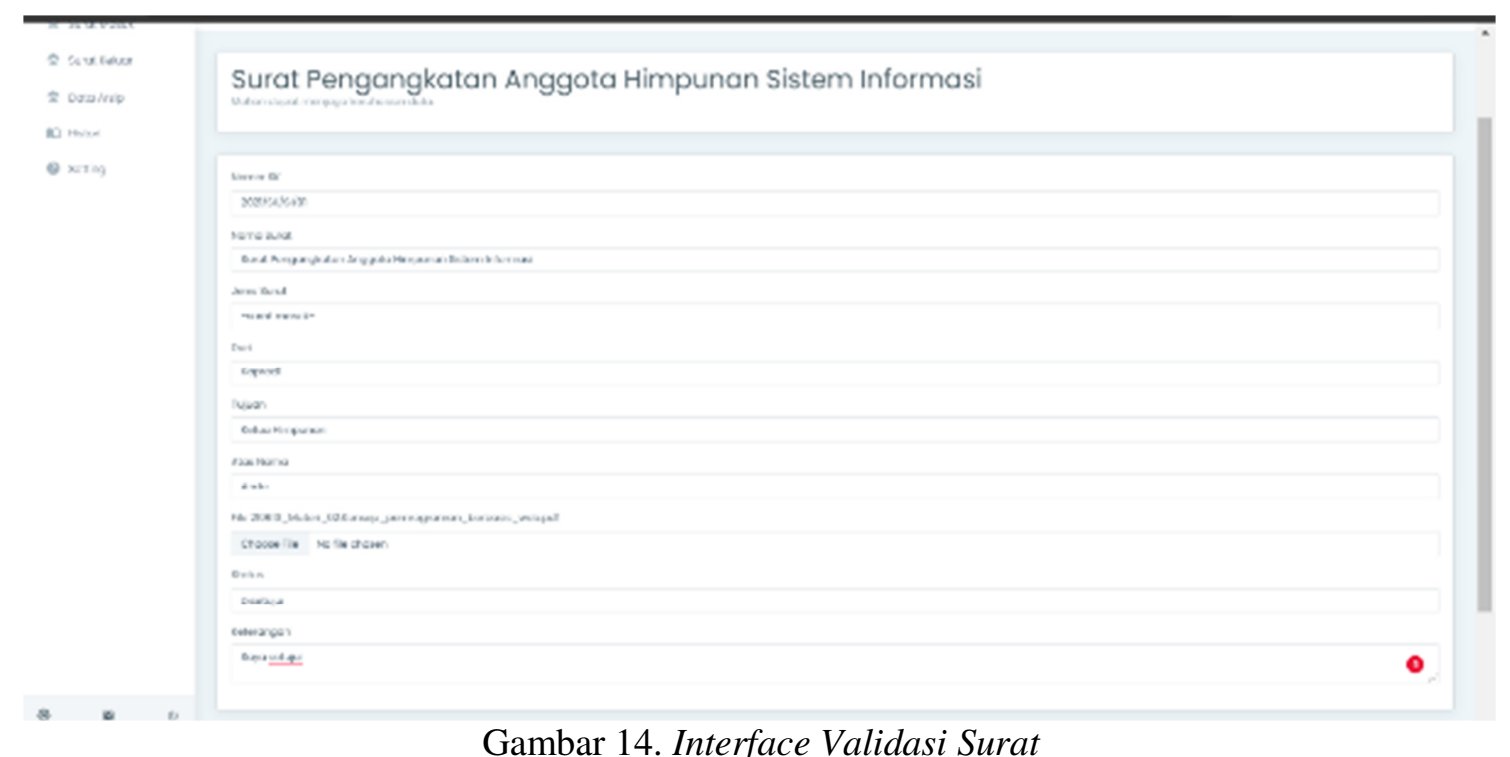

Gambar 14. Interface Validasi Surat

Pada gambar 14 merupakan tampilan validasi surat yang akan disetujui atau tidak oleh kaprodi. Halaman ini hanya bisa diakses oleh kaprodi saja. Kaprodi dapat memberikan masukan atau keterangan pada form keterangan.

\subsubsection{Pengujian Sistem}

Pada proses terakhir ini yaitu pengujian sistem pada sistem E-Arsip menggunakan pengujian procedural dengan teknik black box testing. Pengujian ini mengeuji secara proses alur bisnis yang berlaku pada sistem agar sesuai dengan kaedah dan requirement yang telah ditetapkan. Berikut hasil dari pengujian black box dijelaskan pada table 1.[8][9]

Tabel 1. Pengujian Black Box Sekretaris

\begin{tabular}{cll}
\hline NO & \multicolumn{1}{c}{ Skenario } & Hasil Pengujian \\
\hline 1. & Proses login sebagai sekretariat & Berhasil \\
2 & Melihat data surat masuk & Berhasil \\
3 & Menambah data surat masuk & Berhasil \\
4 & Mengedit data surat masuk & Berhasil \\
5 & Menghapus data surat masuk & Berhasil \\
6 & Melihat data surat keluar & Berhasil \\
7 & Mengunduh arsip & Berhasil \\
8 & Mengubah password & Berhasil \\
9 & Logout & Berhasil \\
10 & Melihat histori & Berhasil \\
\hline
\end{tabular}

Pada tabel 1 merupakan hasil dari pengujian sistem yang berfokus pada sekretaris. Dalam sistem ini sekretaris berperan dalam mengelola data surat masuk dan keluar. Dari akhir pengujian ini, sistem dapat berjalan dengan baik sesuai yang diinginkan penulis.

Putra, et., al [Implementasi Metode Rapid Application Development (RAD) dan Metode Alphabetical Filling pada E-Arsip di Fakultas Matematika dan IPA Berbasis Web 
Tabel 2. Pengujian Black Box Kaprodi

\begin{tabular}{cll}
\hline NO & \multicolumn{1}{c}{ Skenario } & Hasil Pengujian \\
\hline 1. & Proses login sebagai kaprodi & Berhasil \\
2 & Menambah admin & Berhasil \\
3 & Melihat data surat masuk & Berhasil \\
4 & Melihat data surat keluar & Berhasil \\
5 & Mengvalidasi surat masuk & Berhasil \\
6 & Melihat data arsip & Berhasil \\
7 & Mengunduh arsip & Berhasil \\
\hline
\end{tabular}

Pada table 2 merupakan hasil dari pengujian sistem yang berfokus pada kaprodi. Dalam sistem ini kaprodi berfokus pada vallidasi data surat masuk untuk disetujui atau tidak sebelum masuk ke data arsip. Dari akhir pengujian ini, sistem dapat berjalan dengan baik sesuai yang diinginkan penulis.

\section{KESIMPULAN}

Implementasi Sistem E-Arsip pada studi kasus Fakultas Matematika dan IPA di Universitas Semarang dapat membantu dan memudahkan pekerjaan pada program studi dan fakultas dalam melayani surat masuk dan keluar pada data arsip fakultas. Data yang terintegrasi pada satu server memberikan efesiensi pada informasi dan keputusan yang diambil dalam pelayanan sekretariat. Metode Rapid Application Development atau lebih dikenal RAD dalam metode kerangka kerja pada sistem E-Arsip terbukti efesien karena waktu pengembangan yang relative singkat, cepat dan tepat sasaran. Dan Penggunaan Metode Alphabetical Filling pada sistem E-Arsip ini untuk proses pencarian data surat keluar dan surat masuk akan lebih cepat karena data-data sudah tersimpan dengan aman dan terstruktur, Sehingga tidak akan terjadi lagi keterlambatan dalam pencarian data. Pengujian yang dilakukan dengan black box dapat memberikan keberhasilan pada proses bisnis yang diharapkan. Sistem E-Arsip dapat berjalan dengan baik dan hasil output sesuai dengan apa yang di request ke server.

\section{SARAN}

Penulis menyadari bahwa penelitian ini jauh dari kata sempurna, untuk itu penulis sangat menghargai atas kritik dan saran yang akan diberikan oleh para dosen pembimbing berharap dapat diberikan kritik, saran, serta bimbingan dari para dosen agar kedepannya menjadi lebih baik lagi.

\section{UCAPAN TERIMA KASIH}

Penulis mengucapkan terima kasih kepada Bapak Ucuk Darusalam dan Bu Ratih Titi Komala sari yang sebagai dosen pembimbing saya yang telah memberi dukungan terhadap penelitian ini. 


\section{DAFTAR PUSTAKA}

[1] Nugeroho Dimas. "Rancang Bangun Sistem Informasi Monitoring Rencan Strategi Bisnis Bank X Menggunakan Metode RAD. Jurnal Ilmiah Informatika Komputer. Vol. 24 No. 1, April 2019.

[2] Dwi Wijaya Yahya. "Penerapan Metode Rapid Application Development (RAD) Dalam Pengembangan Sistem Informasi Data Toko. Jurnal Sistem Informasi dan Teknologi. Vol. 3, No. 2. E-ISSN: 2622-2973. Desember 2020.

[3] Dedi Irawan Muhammad, Aprilla Simargolang Selli. "Implementasi E-Arsip pada Program Studi Teknik Informatika”. Jurnal Teknologi Informasi. Vol. 2. No 1, E-ISSN 2615-2738. Juni 2018.

[4] Suryadi Ade, Siti Zulaikhah Yuli. "Rancang Bangun Sistem Pengelolaan Arsip Surat Berbasis Web Mengggunakan Metode Waterfall (Studi Kasus: Kantor Desa Karangrau Banyumas)". Jurnal Khatulistiwa Informatika. Vol. VII, No. 1, e-ISSN: 2579-633X. Juni 2019.

[5] Aditra Pradnyana Gede, Aan Jiwa Permana Agus. 2017. "Pengembangan Electornic Letter Management System Berbasis Web (Studi Kasus: Fakultas Teknik dan Kejuruan Undiksha)”. Seminar Nasional Riset Inovatif. ISBN: 978-602-6428-11-0.

[6] Elyana Instianti, Kholil Ishak, Eduard Schaduw Frans. "Rancang Bangun Sistem Informasi Manajemen Disposisi Surat Menyurat Dengan Menggunakan Model RAD (Rapid Application Development). Jurnal Riset Informatika. Vol. 1 No. 2. E-ISSN: 26561735. Maret 2019.

[7] Falihul Isbah Ahamad, Latifah Khoiriya. "Rancang Bangun Sistem Informasi Pendataan Peserta Praktik Kerja Lapangan di Radio RRI Semarang”. Science and Engineering National Seminar. ISBN: 978-623-91160-4-0.4 Desember 2019.

[8] Landjamara Ndjurumana Fredrik, Mailoa Evangs. "Rancang Bangun Sistem Informasi Kerjasama Universitas Kristen Satya Wacana”. Jurnal Teknologi Informasi. Vol 17. No 2. E-ISSN 2615-7128. Agustus 2020.

[9] Chusyairi Ahmad, Rudiawan Bintar, Sasongko Eko. "Layanan Laporan Kehilangan (EReport) Dengan Metode Rapid Application Development”. Jurnal Telematika. Vol. 11 No. 1. e-ISSN: 2442 - 4528. Februari 2018.

[10] Purnama Sari Gusti, Marzal Jefri, Mauladi. "Rancang Bangun Sistem Informasi Persuratan dan Disposisi Elektronik Universitas Jambi”. (JUSS) Jurnal Sains dan Sistem Informasi. Vol 1. No. 1. ISSN 2614-8277 Maret 2018.

[11] Resti Ria, Listiyoko Langgeng, dkk. "Sistem Pengelolaan Dokumen Surat Menggunakan Metode Alphabetical Filing dan Chornology System”. Jurnal Komputer dan Informatika. Vol 15. No. 1. ISSN: 1410-7228 Januari 2020. 
[12] Septiani Noer Azni, Haitami Deden. "Perancangan Sistem Pengarsipan Surat Masuk dan Surat Keluar pada Desa Kampung Besar Menggunakan Metode Alphabetical Filing dan Choronolgy System”. Jurnal Ilmiah Universitas Batanghari Jambi. ISSN: 1411-8939. Juli 2020. 